\title{
O jogo da mala como recurso psíquico em vivências de pré-embarque por parte de jovens intercambistas
}

\section{The "Suitcase Game" as a psychic resource in pre-boarding experiences by young exchange students}

Artigo

Original

\section{Thomás Gomes Gonçalves ${ }^{1}$}

\author{
Original \\ Paper \\ Recebido em \\ $02 / 2013$ \\ Aprovado em \\ $04 / 2013$
}

\section{Palavras-chave: \\ Intercâmbio Cultural}

Psicanálise

Jogo da mala

Betweenbound

\section{Resumo}

O presente artigo tem como objetivo discutir a travessia de jovens intercambistas entre o momento de sua partida para um novo país, deixando sua terra natal, e aquele, após morarem um período fora, no qual estão prestes a retornar para seu país de origem. Para tanto, propõe-se o termo betweenbound para dar conta dessas situações de passagem que exigem do jovem intercambista uma demanda de trabalho psíquico. Ademais, utiliza-se a expressão jogo da mala, baseada no jogo do carretel (fort-da) descrito por Freud, para explicar uma saída psíquica possível para o jovem intercambista frente às separações e incertezas. Discute-se, também, o processo necessário de trabalho de luto, em que se faz necessário o movimento de investir e desinvestir naquilo que lhe é mais conhecido naquele momento para poder enfrentar um processo de intercâmbio cultural.

\section{Abstract}

The article has as its aim to discuss the journey in which exchange students go through between the moment of going to a new country and leaving the native land, as well as when they had already lived some time abroad and they are about to return home. For such, it is proposed the term betweenbound in order to take into account of these situations of crossing which demands from the exchange student a psychic work demand. Besides that it is used the expression the suitcase game, based on the fort-da game described by Freud in order to explain a possible psychic way out to the exchange student facing the separations and to the uncertain moments, besides the necessary process of mourning work in which it is necessary the movement of investing and disinvesting in which is more familiar at that moment to face the process of cultural exchange.
Keywords:

Cultural Exchange

Psychoanalysis

The Suitcase Game

Betweenbound. 


\section{Introdução}

\section{Segundo a BELTA (Brazilian} Educational and Language Travel Association), associação que reúne as principais agências que comercializam estudos no exterior, cerca de 215 mil brasileiros procuraram fazer um programa de intercâmbio cultural no exterior em 2011, sendo que esse número deve aumentar para 280 mil estudantes em 2012 (BELTA, 2012). As opções no mercado para realizar estudos em outros países são as mais variadas, como au pair, estudos em high school, cursos de idiomas, estágios, MBA, entre outros. A opção de realizar intercâmbio em high school tem sido amplamente difundida na cultura e escolhida como preferencial para se ter uma experiência no exterior. Essa modalidade contempla adolescentes que pretendem cursar o último ano do ensino médio fora do seu país de origem.

Ao adentrarmos nesse mundo, observa-se que os programas que possibilitam uma experiência no exterior possuem nomenclaturas específicas para designar o momento no qual o intercambista está vivenciando essa experiência. $\mathrm{O}$ estudante vai passar pela seguinte sequência: outbound (saída do país natal) inbound (chegada ao país onde se realizará o intercâmbio) - rebound (volta ao país natal). Não há, no entanto, uma nomenclatura específica para designar os momentos em que se deixa uma posição para ingressar na outra. Propõe-se, a fim de entender e explorar esses momentos entre outbound e inbound, assim como entre inbound e rebound, a nomenclatura betweenbound, com o intuito de dar conta dessas travessias vividas pelos jovens intercambistas que não se sentem nem aqui e nem lá, ou seja, nem no seu país natal e nem no lugar que os irá receber, o que também ocorre quando passam um período fora e estarão retornando para o seu país de origem.

O termo betweenbound congrega a junção de dois vocábulos e, ao consultar o Dicionário Oxford (2005) em relação a between, tem-se como definição as seguintes ideias: como preposição, between designa a separação no espaço de dois ou mais pontos, objetos, pessoas etc.; período de tempo que separa dias, anos, eventos etc.; separação de um lugar a outro; usado para mostrar conexão ou relação. Além disso, consta a expressão idiomática betwist and between, que se refere a uma posição do meio, que não é nem uma coisa, nem outra. Já a palavra bound comporta os seguintes significados: fronteira, limite, prestes a (OXFORD, 2005). Assim, propõe-se, neste artigo, a reflexão sobre o que acontece quando o jovem justamente se sente neste estado de meio, de intervalo, de between um estado e outro, não se sentindo por completo em um lugar e nem ainda em um outro que virá a seguir.

Dessa forma, é importante ressaltar que é inegável que uma experiência no exterior coloca qualquer sujeito frente a intensas e complexas demandas psíquicas. $\mathrm{O}$ fenômeno do intercâmbio cultural impõe muitos questionamentos e aporta diversas facetas a serem pensadas. Desse modo, frente à grande demanda de indivíduos procurando uma experiência internacional, cabe refletir sobre algumas implicações psíquicas acerca desta situação em que um jovem busca estudar no exterior. Precisamente, este trabalho abarca momentos específicos dessa travessia, isto é, o momento do pré-embarque desses jovens tanto para ir quanto para voltar do exterior, contemplando aspectos psiquicamente significativos desses momentos. Explorar os momentos de betweenbound é necessário, pois é nessas transições que ocorrem, possivelmente, as maiores demandas de angústia ao jovem intercambista, pois este fica dividido entre dois mundos, não se sentindo pertencente a nenhum deles, uma vez que um será temporariamente abandonado, e o outro, todavia, ainda é desconhecido, tendo, dessa forma, que tolerar as incertezas e as poucas garantias.

Para tanto, neste artigo propõe-se, além da utilização do termo betweenbound, a expressão jogo da mala, baseando-se no jogo do carretel (fort-da) descrito por Freud (1920) para dar conta de explicar uma saída psíquica para o jovem intercambista frente às separações e aos momentos de incertezas, além do processo necessário de trabalho de luto em que se faz necessário o movimento de investir e desinvestir. Ademais, este artigo irá explorar essas vicissitudes a partir de textos psicanalíticos, pois tal embasamento pode permitir melhor compreensão e aprofundamento da complexidade inerente às relações humanas e aos processos subjetivos, sempre 
levando em consideração a singularidade do sujeito (DOCKHORN; MACEDO, 2008; DOCKHORN, 2010).

\section{Rumo à independência e à autonomia do sujeito psíquico}

A ida para o exterior, muito possivelmente, não será a primeira separação entre pais e filhos, tendo em vista que ocorreram outras situações ao longo da vida que prenunciaram esse fato, como, por exemplo, a saída dos pais para irem para o trabalho, a entrada do filho na escola, a primeira vez em que o filho dorme fora de casa, etc. Sabe-se que essas experiências demonstram que as separações são importantes tanto para os pais quanto para os filhos, pois permitem um movimento de independência do filho. Por mais que seja algo dado como natural no curso da vida, isto é, que os filhos cresçam e aos poucos vão ganhando o mundo, as separações podem ser sentidas como dolorosas e angustiantes, angústia esta que pode estar presente tanto de um lado quanto de outro.

A experiência de intercâmbio deflagra uma vivência em que se acentua a separação entre os pais e os filhos, por uma questão que vai além da geografia, mas, principalmente, por uma questão de tolerar a distância, o tempo e os sentimentos que estão envolvidos nesse período. De que recursos dispõem estes jovens para poderem lançar mão em tempos de longa separação, como é o caso de intercâmbios high school, em que um jovem permanece longe de casa por um período de até um ano?

Com o intuito de refletir acerca da separação que se dá com a ida do intercambista para o país estrangeiro, é importante percorrer o processo que um sujeito atravessa em sua história rumo à sua própria independência. Para tanto, aborda-se esse tópico a partir do pensamento da psicanalista Margaret Mahler acerca da independência que o sujeito vai adquirindo ao longo da vida.

Margaret Mahler traz importantes contribuições sobre o processo de separação e de individuação de uma criança, principalmente naquilo que se refere a uma separação, primeiramente física, da mãe, por meio da aquisição das capacidades de locomoção, para que, em um momento posterior, possa internalizar a figura desta. Dessa maneira, Mahler (1982) assevera que, para que a criança possa se individuar, é necessário que ela passe por três fases, a saber, a fase de autismo normal, a fase simbiótica e a fase de separação-indivuação, sendo que esta última se divide em quatro diferentes subfases.

A fase de autismo normal (do nascimento até o segundo mês) corresponde à impossibilidade por parte do bebê de perceber e diferenciar as realidades externa e interna, isto é, o bebê não se diferencia do mundo ao seu redor. Já a fase simbiótica (do segundo mês até o quinto mês) diz respeito ao bebê passar a perceber vagamente certas diferenças ao seu redor, ou seja, ocorre uma diferenciação rudimentar no ego, principalmente no que se refere à percepção da criança de que as suas tensões, como a fome, por exemplo, são sanadas por alguém que não é ela, enquanto que o acúmulo de tensão é gerado dentro dela (MAHLER, 1982).

A última fase, separação-individuação (ao redor dos cinco meses), se divide em quatro outras fases: diferenciação, exploração, reaproximação e desenvolvimento da capacidade cognitiva. A subfase de diferenciação (início aos cinco ou seis meses) contempla a “diminuição da dependência corporal da mãe, até então total. Essa subfase coincide com a maturação das funções parciais de locomoção, como engatinhar, trepar e levantar-se" (MAHLER, 1982; p. 36). Nessa subfase, o bebê abrange seu campo de visão imediato, mostrando interesse nos objetos, tendo, dessa forma, uma especial atenção com o mundo externo, na espera de que ele lhe dê prazer e estímulos. Na segunda subfase, exploração (10 meses até 15 meses), o bebê aumenta sua capacidade de locomoção e passa a rastejar e a engatinhar, logo, passa a se distanciar da mãe e a se aventurar longe dela, voltando para perto apenas ocasionalmente, para ter com ela um "reabastecimento emocional". Além disso, o bebê tende a aceitar ir com outros adultos que não sejam a sua mãe e com os quais ele já esteja familiarizado. Na terceira subfase, reaproximação (dos 14 aos 22 meses), a criança começa a caminhar, autorizando-se a separar-se da mãe, provocando um prazer do domínio que agora possui. 
Ao passo que a criança percebe que pode sair de perto da mãe, ao mesmo tempo sente uma necessidade de tê-la por perto para poder partilhar com ela cada aquisição, bem como suas novas habilidades e experiências. Em relação aos sinais de perigo em potencial nessa fase, Mahler (1982) aponta algumas características tais como: a grande ansiedade de separação, seguir a mãe por toda parte ou fugir dela para que ela o persiga, além de perturbações do sono que representam uma regressão e uma experiência de separação (MAHLER, 1982). Sobre esta penúltima subfase, Figueiredo (2003) afirma que "a pequena criança sofre simultaneamente do medo de ir 'longe demais' na sua autonomia com o risco de perder-se do objeto (ser rejeitada ou esquecida por ele) e, em contrapartida, do medo de retornar excessivamente ao raio de controle deste objeto e ser por ele novamente engolfada e invadida" (p.85).

A quarta e última fase (dos 20 ou 22 meses até os 30 ou 36 meses) descrita por Mahler (1982) diz respeito ao desenvolvimento da capacidade cognitiva, como, por exemplo, a comunicação verbal, a fantasia e o critério de realidade, bem como a uma rápida diferenciação do eu, o que possibilita com que a criança se diferencie da mãe e crie, desse modo, representações mentais que permitam a distinção entre o que é dela e o que é do outro. Espera-se que a criança possa então chegar a uma constância objetal em que a figura real da mãe não precise ser tão constante. Para que isso seja possível, é necessário que a criança consiga internalizar e representar a figura da mãe. Sobre a constância objetal, Figueiredo (2003) afirma que "corresponde a uma relativa permanência e integração dos objetos" (p.85).

Para que essas fases descritas por Mahler (1982) possam ocorrer, é necessário que a criança conte desde o seu nascimento com uma mãe suficientemente boa, conceito este proposto pelo psicanalista Donald Winnicott. A mãe suficientemente boa é uma "mãe capaz de reconhecer e atender à dependência do lactente, devido à sua identificação com ele, a qual permite-lhe saber qual é a necessidade do bebê, num dado momento, e responder a ela" (DIAS, 2003; p.133). Além disso, a mãe suficientemente boa viabiliza com que o seu filho tenha a capacidade para estar só. Winnicott (1958) não compreende a solidão como algo maléfico ao sujeito e, sim, como altamente sofisticado e satisfatório, sendo um dos sinais mais importantes do amadurecimento do desenvolvimento emocional. Essa capacidade de ficar só, segundo o autor, é "a experiência de estar só na presença de alguém" (p.37), isto é, para que um sujeito alcance essa capacidade foi necessário que, no início de sua vida, ele tenha tido contado com o auxílio primordial de sua mãe ou de sua substituta, assegurando-lhe, dessa forma, a sua existência. Uma mãe devotada ao seu filho no início de sua vida faz com que o lactente internalize um objeto bom em seu psiquismo, servindo-lhe, então, como protótipo para situações futuras, em que um sujeito pode, dessa maneira, se sentir confiante e seguro em relação a outras situações que se darão em sua história. Para que um sujeito possa se sentir genuinamente sozinho na vida adulta e se sentir bem dessa forma, foi necessário que nos primórdios de sua vida tivesse uma mãe que "nos dias e semanas iniciais, estava temporariamente identificada com o seu lactente, e na ocasião não estava interessada em mais nada que não fosse o seu cuidado" (WINNICOTT, 1958; p.37).

Para que essa capacidade para ficar só aconteça, é preciso, além dos cuidados maternos essenciais, recursos psíquicos por parte da mãe que possibilitem a ela encarar seu filho como alguém que consegue ficar sozinho sem a presença constante dela. Assim,

\footnotetext{
“o que é crucial é que a criança adquira uma identidade, na medida em que a mãe tem uma representação da criança, não como parte dela, senão como alguém separado dela. Na mãe está presente, desde o próprio momento do nascimento, que isso que ela produz não é uma parte dela, mas um bebê que tem a ver com sua relação com o homem, e que, portanto, deve haver nela um projeto que é um projeto de filho e não de maternidade" (HORNSTEIN, 1991; p.174).
}

Ao falar sobre um projeto de filho e um projeto de maternidade, Hornstein (1991) está discorrendo sobre os conceitos da psicanalista Piera Aulagnier sobre o desejo de 
filho e o desejo de maternidade. O primeiro diz respeito a um desejo genuíno por parte da mãe de ter um filho como um sujeito novo e diferenciado dela, já o desejo de maternidade traz em seu bojo o desejo desta mãe de repetir com o seu filho de maneira especular a mesma relação que teve com a sua própria mãe; o filho, nesta situação, uma parte da mãe, ou seja, alguém indiferenciado (HORNSTEIN, 1991).

Salienta-se que, para que um sujeito possa se individuar e se separar, foi necessária a presença de uma mãe nem muito boa nem muito má, apenas suficiente, e que pudesse, desse modo, desempenhar seu papel ao se apresentar como um objeto bom ao seu filho, podendo fazer com que este, dessa maneira, pudesse se sentir seguro e confiante em situações futuras para ter a capacidade de estar só. Um exemplo de uma situação futura pode ser a vivência de um intercâmbio no exterior. Cabe destacar que a forma como se darão as separações inerentes a uma experiência no exterior terá uma estreita relação com as outras separações que se deram ao longo da vida desse jovem. Logo, há uma diferença clara entre uma mãe com um desejo de filho - de certo ponto, uma mãe que pense em ter um filho para o mundo, um cidadão deste, e que na sua presença possa instrumentalizar o filho a ter uma capacidade de tolerar e estar bem consigo, mesmo para que, em situações posteriores, possa lidar bem com esse tipo de experiência - e aquela mãe com um desejo de maternidade, que não oportuniza um espaço para que o filho seja alguém diferente dela, um filho que possa se independentizar.

É interessante notar que, possivelmente nos momentos de entre (betweenbound) - entre outbound e inbound, e entre inbound e rebound -, as subfases exploração e reaproximação, da última etapa proposta por Margaret Mahler, e de separação-individuação parecem se reproduzir nessas vivências de entre, trazendo à tona a importância do papel que a mãe desempenhou para que essas subetapas se dessem de maneira satisfatória. Mostra-se necessário que o jovem possa querer explorar o mundo ao seu redor, não o mundo na perspectiva do bebê, mas o mundo na perspectiva de um adolescente que está ávido para conquistar e conhecer diferentes situações que o mundo possa oferecer, assim como, um senso de ter ido longe demais e querer se reaproxi- mar dos objetos conhecidos para não perder as suas referências.

Porém, como é viabilizado esse trânsito caracterizado pelo entre fronteiras ou betweenbonds? Sabe-se que, antes de embarcar, jovens intercambistas passam por um período turbulento em que não se sentem nem pertencentes ao país de origem nem ao país em que irão morar. Ficam presos, assim, em uma eterna despedida dos amigos e da família, não podendo fazer planos a longo prazo, pois a data de embarque os impede de traçar metas e compromissos nesse período. Esse momento pode ser vivido com certa angústia, insegurança e incerteza. Algumas perguntas podem passar na cabeça do intercambista, como, por exemplo: Como será a família com que irei morar? Conseguirei me adaptar? Como será a escola? Conseguirei fazer amigos? Vou conseguir aguentar ficar longe dos meus pais, dos meus amigos, do meu país? Como se dá então, esse desprendimento saudável em busca da transição de uma posição para outra em um intercâmbio cultural?

\section{Nem lá, nem cá: vivências do entre}

Propõe-se pensar que, para que o intercambista possa fazer este movimento psíquico de separação dos pais e daquilo que ele mais conhece como familiar, é preciso que se faça um trabalho de luto com aquilo que ele está abandonando temporariamente, para poder, dessa forma, se adaptar a uma nova cultura e aos novos objetos que irá encontrar. Logo, para que um intercambista possa ingressar em um novo mundo que o espera, ele terá que desinvestir o mundo e os objetos que ele está deixando, isto é, ele provavelmente só conseguirá investir no intercâmbio e conseguir assim realizar um processo satisfatório e uma adaptação eficaz, caso ele consiga desinvestir os laços que o ligam a suas origens na sua terra natal. O mesmo ocorre na volta do intercambista, no sentido de poder se readaptar à cultura e aos costumes que temporariamente abandonou. 
Freud (1917), em seu texto "Luto e Melancolia", descreve o luto como a "reação à perda de uma pessoa amada ou de uma abstração que ocupa seu lugar, como pátria, liberdade, um ideal etc.” (p.171). O autor, no entanto, não considera o luto como algo patológico e que necessariamente precise de tratamento para ser combatido. Assim, o luto é superado após algum tempo, sem a necessidade de perturbá-lo, podendo ser, caso haja uma intervenção, até mesmo prejudicial. Por outro lado, Freud (1917) afirma que, em certos sujeitos, ao invés de se presentificar um luto normal frente à perda de um objeto, o que acontece é uma melancolia. $\mathrm{O}$ autor define a melancolia como um "abatimento doloroso, uma cessação do interesse pelo mundo exterior, perda da capacidade de amar, inibição de toda atividade e diminuição da autoestima" (p.172). Diferentemente da melancolia, o sujeito que está atravessando um luto normal não vê sua autoestima afetada.

Ao não conseguirem fazer esse trabalho de luto, observa-se, por exemplo, que certos intercambistas, ao chegarem no país hospedeiro, tentam se manter ligados ao país de origem e aos pais , não conseguindo desinvesti-los para investir na sua situação atual. Exemplo disso é a tentativa dos jovens de permanecerem sempre ligados a figuras de referência por meio da Internet. Assim, mantendo-se ligados, esses jovens tentam conservar a ilusão de que ainda estão ligados de alguma forma com aquilo que deixaram para trás. Nesse sentido, Escobari (2009) afirma que muitos estrangeiros não conseguem se descolar do objeto, por exemplo, mantendo as infindáveis e custosas ligações telefônicas internacionais, e complementa: "aqui o carretel não se tranforma em jogo, e sim como um fio, ou linha, lançado à distância, mantém uma ponta presa à outra, servindo justamente para que a migração funcione nesse lugar onde a separação nunca se dá” (p.87).

Propõe-se pensar, então, que a mala que o jovem intercambista leva consigo, do seu país natal até a nova pátria em que irá morar, proporciona com que ele faça esse trabalho de luto, além desse movimento de investimento e desinvestimento, pois é notável a relação especial que o intercambista possui com a sua mala. A bagagem está equipada com aquilo que o jovem leva do seu mundo referente à sua vida no país de origem e, ademais, também está carregada de sentimentos e investida de lembranças daquilo que deixou para trás. $\mathrm{O}$ intercambista carrega o que lhe lembra do seu lugar de referência, assim como leva muito do seu mundo interno. A mala representa a tentativa de levar junto consigo os seus amigos, seus familiares, uma garantia de que, por mais que o jovem esteja no estrangeiro, haverá algo de familiar, de conhecido, sempre ao seu lado.

Observam-se, também, o medo e o receio que os intercambistas sentem perante a possibilidade de perder a sua mala durante as conexões e escalas até chegar ao seu destino, como se, ao perder a mala, estivessem perdendo também a si mesmos. O mesmo ocorre com o jovem que está prestes a retornar para seu país natal, que, por meio de sua mala, tenta levar aquilo que construiu no exterior para seu país de origem, também em uma tentativa de não esquecer o que foi vivido, de manter as ligações com o lugar em que morou, além de possibilitar uma readaptação mais satisfatória, viabilizando um outro trabalho de luto pelo que deixa no seu país hospedeiro.

Assim, baseado no jogo do carretel (fort-da) descrito por Freud (1920), propõe-se que, em tempos de intercâmbio, a mala faz as vezes do carretel, substituindo-o para que o intercambista possa dar conta da demanda de poder sair do seu país e, assim, adentrar em um novo território, tal como no seu regresso. Freud (1920) descreve esse jogo baseado em observações de seu próprio neto, quando

\footnotetext{
“esse bom menino tinha o hábito, ocasionalmente importuno, de jogar todos os pequenos objetos que alcançava para longe de si, a um canto do aposento, debaixo da cama etc., de modo que reunir os seus brinquedos não era coisa fácil. Ao fazer isso ele proferia, com expressão de interesse e satisfação, um forte e prolongado o-o-o-o, que, no julgamento da mãe e no deste observador, não era uma interjeição e significava 'fort' (foi embora). Afinal percebi que era um jogo e que o menino apenas usava todos os seus brinquedos para jogar 'ir embora'. Um dia pude fazer a observação que confirmou minha opinião. Ele tinha um carretel de madeira, em que
} 
estava enrolado um cordão. Nunca lhe ocorria, por exemplo, puxá-lo atrás de si pelo chão, brincar de carro com ele; em vez disso, com habilidade lançava o carretel, seguro pelo cordão, para dentro do berço, através de seu cortinado, de modo que ele desaparecia, nisso falando o significativo o-o-o-o, e depois puxava novamente para fora do berço, saudando o aparecimento dele com um alegre ' $d a$ '(está aqui). Então era essa a brincadeira completa, desaparecimento e reaparição, de que geralmente via-se o primeiro ato, que era repetido incansavelmente como um jogo em si, embora sem dúvida o prazer maior estivesse no segundo ato" (p.172).

Observa-se comumente que, ao chegarem em suas casas hospedeiras e no quarto onde irão dormir junto a essas famílias, os intercambistas transformam o quarto em seu território, isto é, colocam fotos de seus familiares na parede, penduram a bandeira de seu país etc., numa tentativa de que o estrangeiro lhes pareça um pouco mais familiar. Assim, o esvaziar da mala demonstra que aos poucos os intercambistas vão desinvestindo o mundo que deixaram para trás; e espera-se que a mala que trouxeram de seu país vá sendo esquecida e o que estava dentro dela já esteja posicionado na casa da família que os está hospedando. Novamente, a mala passa a desenvolver um papel importante quando o intercambista se prepara para voltar ao seu país de origem. O que levar do país hospedeiro? E o mesmo processo se repete, o intercambista irá decidir o que levar daquele lugar em sua mala, para no regresso ao seu país natal poder se lembrar daquela experiência que teve. Assim, a bandeira, os souvenirs, as fotos do lugar em que morou passarão a ocupar o quarto no seu país natal. O jogo da mala, em certo ponto, representa aquilo que é material e que não pode ser inscrito por completo psiquicamente, no qual o intercambista tem a chance de levar e trazer, de lançar a mala em um movimento de ir embora e de estar por perto, ajudando-o nessas travessias que estão no entre, no betweenbounds.

\section{Considerações Finais}

Ao considerarmos as implicações psíquicas de se fazer um intercâmbio cultural, é necessário abarcar o momento de betweenbound para compreender melhor o que se passa quando um jovem sai de casa para ir para o exterior, assim como em sua volta. O momento de betweenbound dever estar contemplado entre outbound e inbound na sua ida para o estrangeiro, assim como entre o inbound e rebound no seu retorno ao país natal, pois garante um lugar privilegiado que é o intervalo entre uma posição e outra e que explicita esses movimentos de separação. A mala, então, sai de um lugar puramente material para ser um recurso psíquico possível para a adaptação desse jovem quando está no exterior, assim como no seu retorno. É interessante notar que, em alguns casos, quando a mala é extraviada no caminho até o destino final de seu intercâmbio ou no caminho até o aeroporto onde seus pais o esperam no regresso, parece que o jovem não pode se tranquilizar e efetivar uma transição de uma situação de para outra. A mala permite que o jovem se agarre em algumas coisas fixas em tempos tão transitórios, garantindo-lhe saber quem é e sendo um disparador para situações futuras que virão.

\section{Referências}

BELTA. Imprensa. Disponível em: http://www.belta.org.br/ imprensa/11/ intercambio + cresce $+30+\mathrm{em}+2011$. Acesso em 8 de dezembro de 2012 .

DIAS, E. A teoria do amadurecimento de

D.W. Winnicott. São Paulo: Imago, 2003.

DOCKHORN, C. N. F. B.; MACEDO, M. M. K. A complexidade dos tempos atuais: reflexões psicanalíticas. Revista Argumento Psicologia, v.54 n.26, p.217-224, 2008.

DOCKHORN, C. N. F. B. A psicanálise como instrumento de olhar os tempos atuais. Disponível em http://www.sig.org.br/ files/artigos/ apsicanlisecomoinstrumentodeolharsenostemposatuais. Acesso em 18 de abril de 2012.

ESCOBARI, D. Quem da pátria sai a si mesmo escapa. São Paulo: Escuta. 
FIGUEIREDO, L. Elementos para a clínica contemporânea. São Paulo: Escuta

FREUD, S. Luto e Melancolia. In: SOUZA,P.C (Trad.). Obras completas de Sigmund Freud. São Paulo: Companhia das Letras, 1917/2010. p. 170-194.

Além do princípio do prazer. In: SOUZA,P.C (Trad.). Obras completas de Sigmund Freud. São Paulo: Companhia das Letras, 1920/2011.p. 161-239.

HORNSTEIN, L. (1991). Diálogo con Piera Aulagnier. In: HORNSTEIN, L. Cuerpo, historia, interpretación. Buenos Aires: Paidós, 1991. p. 360-379.

MAHLER, M. A interação mãe-filho durante a separação-individuação. In: $\mathbf{O}$ processo de separação-individuação. Porto Alegre: Artes médicas, 1982.

OXFORD. Advanced learner's dictionary. Oxford: University Press, 2005.

SEBBEN, A. Intercâmbio cultural: um guía de educação intercultural para ser cidadão do mundo. Porto Alegre: Artes \& Ofício, 2007.

WINNICOTT, D. O ambiente e os processos de maturação. Porto alegre: Artmed, 1958.

http://www.sig.org.br/ files/artigos/ apsicanlisecomoinstrumentodeolharsenostemposatuais. Acesso em 18 de abril de 2012.
ESCOBARI, D. Quem da pátria sai a si mesmo escapa. São Paulo: Escuta.

FIGUEIREDO, L. Elementos para a clínica contemporânea. São Paulo: Escuta

FREUD, S. Luto e Melancolia. In: SOUZA,P.C (Trad.). Obras completas de Sigmund Freud. São Paulo: Companhia das Letras, 1917/2010. p. 170-194.

Além do princípio do prazer. In: SOUZA,P.C (Trad.). Obras completas de Sigmund Freud. São Paulo: Companhia das Letras, 1920/2011. p. 161-239.

HORNSTEIN, L. (1991). Diálogo con Piera Aulagnier. In: HORNSTEIN, L. Cuerpo, historia, interpretación. Buenos Aires: Paidós, 1991. p. 360-379.

MAHLER, M. A interação mãe-filho durante a separação-individuação. In: $O$ processo de separação-individuação. Porto Alegre: Artes médicas, 1982.

OXFORD. Advanced learner's dictionary. Oxford: University Press, 2005.

SEBBEN, A. Intercâmbio cultural: um guía de educação intercultural para ser cidadão do mundo. Porto Alegre: Artes \& Ofício, 2007.

WINNICOTT, D. O ambiente e os processos de maturação. Porto alegre: Artmed, 1958. 